\title{
Periodic and continuous inventory models in the presence of fuzzy costs
}

\author{
Soheil Sadi-Nezhad ${ }^{\mathrm{a}^{*}}$, Shima Memar Nahavandi ${ }^{\mathrm{a}}$ and Jamshid Nazemi ${ }^{\mathrm{a}}$
}

${ }^{a}$ Department of Engineering, Science \& Research Branch, Islamic Azad University, Tehran Iran

\section{A R T I C L E I N F O}

\section{Article history:}

Received 10 January 2010

Received in revised form

22 June 2010

Accepted 24 June 2010

Available online 25 June 2010

Keywords:

Fuzzy inventory

Periodic review inventory model

Continuous review inventory

model

Signed distance method

\section{A B S T R A C T}

This paper presents two models, a periodic review model and a continuous review inventory model with fuzzy setup cost, holding cost and shortage cost. We use two methods in the name of signed distance and possibilistic mean value to defuzzify. Also we consider the lead time demand and the lead-time plus one period's demand as random variables. To validate the models and the solution procedures we apply them to a transformer manufacturing, 'Iran transfo', company. Furthermore we design a decision support system which can be used for efficient evaluation of the proposed models in fuzzy environment.

(C) 2010 Growing Science Ltd. All rights reserved.

\section{Introduction}

The increase in global competition especially among the manufacturing sectors motivates many contemporary organizations to spend more efforts for optimizing their global supply chain. Managing inventory as a primary function of supply chain, in an efficient and effective way, plays an important role on reducing the total cost of supply chain. The main purpose of the inventory management practices in all production companies is to have the required items ready in the predefined schedule with incurring minimum cost (Cakir \& Canbolat, 2008). The proper control of their levels usually brings significant savings in costs. The development of inventory theory has evolved since the early 1920s, started with basic models with a few parameters to describe the deterministic components (Kao \& Hsu, 2002). However, in the real world applications, estimating the precise value of parameters like demand and costs may not be possible. What a decision maker faces in this case is a fuzzy environment. In this regard, the preliminary models are changed to include more details using probabilistic models and fuzzy models, to overcome this limitation.

Fuzzy set theory introduced by Zadeh (1963), provides an alternate to handle the vague situations. It has been used in modeling of inventory systems with vague and imprecise parameters since 1980s. In recent years, various types of inventory problems have been developed in fuzzy environments. Yao and Lee (1999) introduced a backorder inventory model with fuzzy order quantity as triangular and trapezoidal fuzzy numbers and shortage cost as a crisp parameter. Yao and Su (2000) developed fuzzy inventory model without backorder by adopting an interval valued fuzzy number for fuzzifying the

* Corresponding author. Tel:(98)(21)22010690./fax: (98)(21)22043001.

E-mail addresses: sadinejad@hotmail.com (S. Sadi-Nezhad), 
total demand quantity. Chang et al. (2004) proposed mixture inventory model involving variable lead time with backorders and lost sales by introducing the fuzziness of lead time demand, the average demand per year and the backorder rate of the demand during the stock-out period. Yao and Chiang (2003) considered the total cost of inventory without backorder. They fuzzified the total demand and cost of storing one unit per day into triangular fuzzy numbers and defuzzified by the centroid and the signed distance methods. Lin (2008) developed the inventory problem for a periodic review model with variable lead time and fuzzified the expected demand shortage and backorder rate using signed distance method to defuzzify. Wu and Yao (2003) fuzzified the order quantity and shortage quantity into triangular fuzzy numbers in an inventory model with backorder and they obtained the membership function of the fuzzy cost and its centroid. Handfield et al. (2009) developed a $(Q, r)$ model based on fuzzy-set including fuzzy parameters like demand, lead time, supplier yield, and shortage cost. They also introduced a human risk attitude factor to quantify the decision maker's attitude toward the risk of stocking out during the replenishment period. The total cost was computed using centroid as defuzzification method. Tütüncü et al. (2009) used fuzzy set concepts to treat the uncertainty regarding costs in models of continuous review inventory control with or without backorder, with fuzzy costs and probabilistic demand then used Park's Median Rule to defuzzify. Vijayan and Kumaran (2008) introduced stochastic $(Q, r)$ and $(R, T)$ inventory models with a mixture of backorders and lost sales. They introduced fuzziness in the cost parameters to study the impact and sensitiveness of the impreciseness of cost components in the decision variables by trapezoidal fuzzy numbers and adopted the signed distance method to estimate the fuzzy cost function of the models. Dey and Chakraborty (2009) developed a periodic review model in a mixed imprecise and/or uncertain environment in which the customer demand, lead-time demand and the lead-time plus one period's demand are assumed to be fuzzy random variables. The fuzzy expected cost is defuzzified by its possibilistic mean value. Table1 shows a summary of literature review.

Table 1

The summery of literature review

\begin{tabular}{|c|c|c|c|}
\hline Author & Year & Fuzzy Parameters & Defuzzification Method \\
\hline Yao and Chiang & 2003 & total demand, holding cost & $\begin{array}{l}\text { Centroid, Signed distance } \\
\text { method }\end{array}$ \\
\hline $\mathrm{Wu}$ and Yao & 2003 & order quantity, shortage quantity & centroid \\
\hline Chang and Yao & 2004 & $\begin{array}{l}\text { total demand, lead time demand, } \\
\text { backorder rate }\end{array}$ & Signed distance method \\
\hline $\begin{array}{l}\text { Tutunchu and } \\
\text { Akoz }\end{array}$ & 2007 & $\begin{array}{l}\text { setup cost, holding cost, shortage cost, } \\
\text { unit cost }\end{array}$ & Median rule \\
\hline $\begin{array}{l}\text { Vijayan and } \\
\text { Kumaran }\end{array}$ & 2008 & $\begin{array}{l}\text { setup cost, holding cost, shortage cost, } \\
\text { lost sale cost }\end{array}$ & Signed distance method \\
\hline Lin & 2008 & $\begin{array}{c}\text { expected demand shortage, backorder } \\
\text { rate }\end{array}$ & Signed distance method \\
\hline $\begin{array}{l}\text { Dey and } \\
\text { Chakraborty }\end{array}$ & 2009 & $\begin{array}{l}\text { total demand, lead-time demand and the } \\
\text { lead-time plus one period's demand }\end{array}$ & Possibilistic mean value \\
\hline $\begin{array}{l}\text { Handfield, } \\
\text { Warsing }\end{array}$ & 2009 & $\begin{array}{c}\text { demand, lead time, supplier yield, and } \\
\text { shortage cost }\end{array}$ & centroid \\
\hline $\begin{array}{l}\text { Sadinejad } \\
\text { and Memar }\end{array}$ & 2010 & setup cost, holding cost, shortage cost & $\begin{array}{l}\text { Signed distance method, } \\
\text { Possibilistic mean value }\end{array}$ \\
\hline
\end{tabular}

Due to some fluctuations in inventory costs, these parameters are described as "approximately equal to". Therefore, in this research we characterize these parameters as fuzzy variables in a periodic model and a continuous inventory model with backorder. Yao \& Chiang (2003) introduced the vantage of signed distance method comparing to centroid method and we prefer to use this method. 
Also for the ease of computation we use Possibilistic mean value as another method for deffuzification (Day \& Chakraborty, 2009).

This article is organized as follows: Section 2 reviews some definitions and properties about fuzzy sets and defuzzification methods which would be used later. Section 3, deals with the methodology where the models and their optimal solutions are discussed. The subsection 3.1 explores the inventory problem for a periodic review and subsections 3.1.1 and 3.1.2 describes the defuzzified model by signed distance method and possibilistic mean value method. Section 3.2 introduces the continuous review inventory model in which section 3.2.1 and 3.2.2 are related to its defuzzification through signed distance and possibilistic mean value methods, respectively. Section 4 shows the results of the models for and Iranian case study called "Iran Transfo". In section 5, a decision support system with a user-friendly interface to obtain efficient solution of the proposed models is presented. Finally, conclusion remarks are given at the end to summarize the contribution of the paper.

\section{Fuzzy preliminaries}

Fuzzy set theory provides an appropriate framework to treat imprecision of modeling uncertainties and it offers more flexibility in describing these uncertainties.

Definition 1. A fuzzy set $\widetilde{a}$ on $R=(-\infty,+\infty)$ is called a fuzzy point if its membership function is as follows,

$\mu_{\widehat{a}}(x)=\left\{\begin{array}{cc}1 & x=a \\ 0 & x \neq a\end{array}\right.$

where $a$ is called its support.

Definition 2. The fuzzy set $\widetilde{A}=(a, b, c)$ is called the triangular fuzzy number where $a<b<c$, if the membership function of $A$ is given by

$\mu_{\widetilde{A}}(x)= \begin{cases}\frac{x-a}{b-a} & a \leq x \leq b \\ \frac{c-x}{c-b} & b \leq x \leq c \\ 0 & \text { otherwise. }\end{cases}$

Definition 3. The $\alpha$-cut of $\widetilde{A}=(\mathrm{a}, \mathrm{b}, \mathrm{c})$ where $0 \leq \alpha \leq 1$ is: $A(\alpha)=\left[A_{L}(\alpha), A_{R}(\alpha)\right] . A_{R}(\alpha)$ and $A_{L}(\alpha)$ are the left and right end points of $A(\alpha)$ and are defined as follow,

$A_{\alpha}^{-}=a+\alpha(b-a), \quad A_{\alpha}^{+}=c-\alpha(c-b)$

Property1. For the fuzzy triangular numbers $\widetilde{A}=(\mathrm{a}, \mathrm{b}, \mathrm{c})$ and $\widetilde{B}=(p, q, r)$ we have,

$$
\begin{aligned}
& \tilde{A}(+) \tilde{B}=(a+p, b+q, c+r) \\
& \tilde{A}(-) \tilde{B}=(a-p, b-q, c-r)
\end{aligned} \quad k(.) \tilde{A}= \begin{cases}(k a, k b, k c), & k>0 \\
(k c, k b, k a), & k<0 \\
0, & k=0\end{cases}
$$


Definition 4. The defuzzification of $\tilde{A}$ can be found by centroid or signed distance methods. The centroid of $\widetilde{A}$ is $C(\tilde{A})=\frac{a+b+c}{3}$ and the signed distance from $\tilde{A}$ to 0 is defined as follows,

$d(\widetilde{A}, \widetilde{0})=\int_{0}^{1} d\left(\left[A_{L}(\alpha), A_{R}(\alpha)\right], \widetilde{0}\right) d \alpha=\frac{a+2 b+c}{4}$

According to Kumaran (2007), it can be concluded that using $d(\widetilde{A}, \widetilde{0})$ to defuzzify a fuzzy number, is better than using $C(\tilde{A})$.

\subsection{Possibilistic mean value of a fuzzy number}

For a given fuzzy number $\widetilde{A}$, the interval-valued possibilistic mean is defined as,

$M(\tilde{A}))=\left[M_{L}(\tilde{A}), M_{R}(\tilde{A})\right]$,

where $M_{L}(\widetilde{A})$ and $M^{U}(\widetilde{A})$ are the lower and the upper values of $\tilde{A}$ and are, respectively, defined by Day and Chakraborty (2009).

$M_{L}(\tilde{A})=\frac{\int_{0}^{1} \alpha A_{\alpha}^{-} d \alpha}{\int_{0}^{1} \alpha d \alpha}$ and $\quad M_{R}(\tilde{A})=\frac{\int_{0}^{1} \alpha A_{\alpha}^{+} d \alpha}{\int_{0}^{1} \alpha d \alpha}$

The possibilistic mean value of $\tilde{A}$ is then defined as,

$\bar{M}(\widetilde{A})=\int_{0}^{1} \alpha\left(A_{\alpha}^{-}+A_{\alpha}^{+}\right) d \alpha$

\section{Methodology}

We make use of the following notations through this paper:

$T$ the time between replenishments;

$R$ target inventory level;

$Q$ lot size in units;

$r$ reorder point;

A unit cost of placing an order for an item;

$h$ inventory holding cost per unit per year;

$\pi$ unit shortage cost;

$D$ annual demand

\section{1 periodic review inventory model}

A periodic review system involves determining the amount of an item in stock at a specified, fixed time interval and placing an order that when added to the quantity on hand, will equal to predetermined maximum level. The target inventory level $R$, is the sum of expected demand during the lead time and replenishment period plus the safety stock. Due to fluctuations in demand or 
variable lead time, stock out may occur, in which case a penalty per unit shortage is incurred. The purpose of the periodic inventory model is to find the optimal time between replenishment and maximum inventory level such that the combination of the order cost and the holding cost and shortage cost is minimized. The approximate mean total cost is expressed as follows,

$C(R, T)=\frac{A}{T}+h\left[R-D L-\frac{D T}{2}\right]+\frac{\pi}{T} B(R, T)$,

where $B(R, T)$ is the expected shortage at the end of the cycle and is defined as follows,

$$
B(R, T)=E\left(D_{L+T}-R\right)^{+}=\int_{R}^{\infty}(x-R) f(x) d x,
$$

where $x$ denotes the lead-time plus one period's demand that follows a normal distribution. $f(x)$ is normal probability distribution function with mean $\mu_{L+T}$ and standard deviation $\sigma \sqrt{T+L}$.

To minimize the $\mathrm{C}(\mathrm{R}, \mathrm{T})$ we solve $\frac{\partial d(C(R, T), 0)}{\partial R}=0$ which yields,

$\int_{R}^{\infty} f(x, T) d x=\frac{h T}{\pi}$.

The complementary cumulative distribution of $x$ is as follows,

$$
R=F^{-1}\left(1-\frac{h T}{\pi}\right)
$$

The initial value of $T$ concludes the value of $R$ and consequently the value of $\mathrm{C}(\mathrm{R}, \mathrm{T})$ can be calculated. This procedure is iterated until the condition $C\left(R_{i-1}, T_{i-1}\right)-C\left(R_{i}, T_{i}\right)>0$ is achieved in stage $i$, which means the cost needs to be decreased until it attains its minimum which yields $T^{*}$ and $R^{*}$ to be $T^{*}=T_{i-1}$ and $R^{*}=R_{i-1}$.

Note that the values of $\mu_{L+T}$ and $\sigma_{L+T}$ must be recalculated in the cumulative distribution function for each iteration.

\subsubsection{Fuzzy periodic review inventory model using signed distance method}

Since evaluating actual costs in real world is very difficult, if not impossible, we consider all costs in the model in fuzzy sense. Consider the fuzzy costs as follows,

$$
\begin{aligned}
& \pi=\left(\pi-\lambda_{1}, \pi, \pi+\lambda_{2}\right), \\
& h=\left(h-\Delta_{1}, h, h+\Delta_{2}\right), \\
& A=\left(A-\delta_{1}, A, A+\delta_{2}\right) .
\end{aligned}
$$

By substituting these fuzzy costs into (4) we get three expected annual costs as follows,

$$
\begin{aligned}
& C_{1}(R, T)=\frac{A-\delta_{1}}{T}+\left(h-\Delta_{1}\right)\left(R-D L-\frac{D T}{2}\right)+E\left(D_{L+T}-R\right)^{+}\left(\frac{\pi-\lambda_{1}}{T}\right), \\
& C_{2}(R, T)=\frac{A}{T}+h\left[R-D L-\frac{D T}{2}\right]+E\left(D_{L+T}-R\right)^{+} \frac{\pi}{T}, \\
& C_{3}(R, T)=\frac{A+\delta_{2}}{T}+\left(h+\Delta_{2}\right)\left(R-D L-\frac{D T}{2}\right)+E\left(D_{L+T}-R\right)^{+}\left(\frac{\pi+\lambda_{2}}{T}\right) .
\end{aligned}
$$


Using the signed distance method given in (2) yields the following defuzzified value of $\mathrm{C}(\mathrm{R}, \mathrm{T})$, $d(C(R, T), 0)=C_{2}+\frac{1}{4}\left[\frac{\delta_{2}-\delta_{1}}{T}+\left(\Delta_{2}-\Delta_{1}\right)\left(R-D L-\frac{D T}{2}\right)+\left(\frac{\lambda_{2}-\lambda_{1}}{T}\right) B(R, T)\right]$.

Similar to the crisp case, the optimal values of $R$ and $T$ are obtained by taking the derivative of $C(R, T)$ with respect to $R$, which yields,

$\int_{R}^{\infty} f(x, T) d x=\frac{\left[h+\frac{\Delta_{4}-\Delta_{3}}{4}\right] T}{\pi+\frac{\pi_{6}-\pi_{5}}{4}}$,

or

$R=F^{-1}\left(1-\frac{\left[h+\frac{\Delta_{4}-\Delta_{3}}{4}\right] T}{\pi+\frac{\pi_{6}-\pi_{5}}{4}}\right)$.

The solution procedure proposed for the crisp case in the previous section is implemented here to find $T^{*}$ and $R^{*}$.

\subsubsection{Fuzzy periodic review inventory model using possibilistic mean value method}

The aim of this section is to use the $\alpha$-cut of the fuzzy inventory costs to derive the $\alpha$-cut of the fuzzy total cost. The $\alpha$-cuts of the setup cost, holding cost and shortage cost are calculated using (1). Substituting the left endpoints of the costs in (4) results the left endpoint of the total cost and the right endpoints results the right endpoint of the total cost as follow,

$C_{\alpha}^{-}=\frac{A_{\alpha}^{-}}{T}+h_{\alpha}^{-}\left[R-D L-\frac{D T}{2}\right]+B(R, T) \frac{\pi_{\alpha}^{-}}{T}$,
$C_{\alpha}^{+}=\frac{A_{\alpha}^{+}}{T}+h_{\alpha}^{+}\left[R-D L-\frac{D T}{2}\right]+B(R, T) \frac{\pi_{\alpha}^{+}}{T}$.

The possibilistic mean value of the above interval through (3) is determined as follows,

$C(R, T)=\int_{0}^{1}\left(C_{\alpha}^{-}+C_{\alpha}^{+}\right) d \alpha$

The procedure to find the optimal values is the same as section 3.1 but $R$ is determined as follows where $u$ is defined as,

$u=1-\frac{h T}{\pi}$

with $\alpha=0$, the two lower edges and with $\alpha=1$, the upper edge of the triangle are made as follows, 
$u_{1}=1-\frac{h_{3} T}{\pi_{1}}, \quad u_{2}=1-\frac{h_{2} T}{\pi_{2}}, \quad u_{3}=1-\frac{h_{1} T}{\pi_{3}}$.

$\alpha$-cut

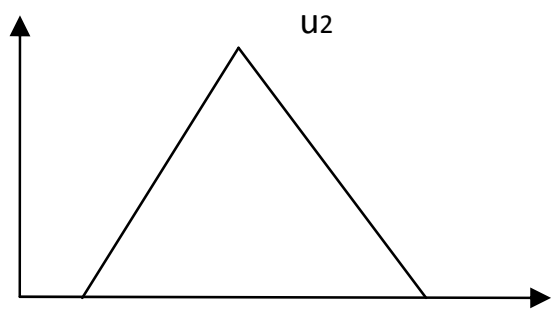

u1

u3

The left and the right endpoints of this interval are as follows,

$u_{\alpha}^{-}=u_{1}+\alpha\left(u_{2}-u_{1}\right)$,

$u_{\alpha}^{+}=u_{3}-\alpha\left(u_{3}-u_{2}\right)$.

Therefore, the defuzzified value using its possibilistic mean value given in (3) is calculated as follows,

$u=\int_{0}^{1}\left(u_{\alpha}^{-}+u_{\alpha}^{+}\right) d \alpha$

and $R$ is also calculated as $R=F^{-1}(u)$.

\subsection{Continuous review inventory system}

In a continuous review inventory system, an order for a lot is placed whenever the quantity on hand is dropped to a predetermined level, known as the order point. The total cost expression of this model used in this paper is presented as follows,

$C(Q, r)=\frac{A D}{Q}+h\left[\frac{Q}{2}+r-\mu\right]+\left(\frac{\pi D}{Q} B(r)\right)$,

where $B(r)$ is the expected demand shortage at the end of the cycle and is defined as follows,

$B(r)=E\left(D_{L}-r\right)^{+}=\int_{R}^{\infty}(x-r) f(x) d x$,

where $x$ is regarded as the value of lead-time demand with normal probability distribution function $f(x)$, mean $\mu_{L}$ and standard deviation $\sigma_{L}$. Taking the first derivative of $C(Q, r)$ with respect to $\mathrm{Q}$ and $\mathrm{r}$ yields the optimal values as follows,

$Q^{*}=\sqrt{\frac{2 D[A+\pi B(r)]}{h}}$, 
$r^{*}=F^{-1}\left(1-\frac{h Q}{\pi D}\right)$

\subsubsection{Fuzzy continuous review inventory model using signed distance method}

By substituting fuzzy parameters in (16) and getting three total costs like the periodic model, the defuzzified cost using signed distance method is determined as follows,

$d(C(Q, r), 0)=C(Q, r)+\frac{1}{4}\left[\frac{\left(\delta_{2}-\delta_{1}\right) D}{Q}+\left(\Delta_{2}-\Delta_{1}\right)\left[\frac{Q}{2}+r-\mu\right]+\left(\frac{\left(\lambda_{2}-\lambda_{1}\right) D}{Q} B(r)\right)\right]$.

Taking the partial derivatives with respect to $\mathrm{Q}$ and $\mathrm{r}$ yields,

$Q^{*}=\sqrt{\frac{2 D\left[A+\frac{\left(\delta_{2}-\delta_{1}\right)}{4}+\left(\pi+\frac{\left(\lambda_{2}-\lambda_{1}\right)}{4}\right) B(r)\right]}{h+\frac{\left(\Delta_{2}-\Delta_{1}\right)}{4}}}$,

and

$r^{*}=F^{-1}\left(1-\frac{\left(h+\frac{\left(\Delta_{2}-\Delta_{1}\right)}{4}\right) Q}{\left(\pi+\frac{\left(\lambda_{2}-\lambda_{1}\right)}{4}\right) D}\right)$.

Since the optimum values of $Q$ and $r$ cannot be directly obtained by Eq. (20) and Eq. (21), the iterative procedure suggested by Hadley and Whitin (1963) is used to solve the equations. The initial value for $Q$ is obtained by equating $\mathrm{B}(\mathrm{r})$ to zero and with the $r$ resulted from substituting $Q$ in (21) and $B(r)$ is obtained by substituting $r$ in (17) and the new $Q$ is obtained by Eq. (20). Repeating this procedure until the condition $Q_{i}=Q_{i-1}$ is met, will lead us to find the optimal values of $Q$ and $r$.

\subsubsection{Fuzzy continuous review inventory model using possibilistic mean value method}

Similar to section 3.1.2, the $\alpha$-cut approach is used to treat the fuzziness and derive the total annual cost as follows,

$$
\begin{aligned}
& C_{\alpha}^{-}(Q, r)=\frac{A_{\alpha}^{-} D}{Q}+h_{\alpha}^{-}\left[\frac{Q}{2}+r-\mu\right]+\left(\frac{\pi_{\alpha}^{-} D}{Q} B(r)\right) \\
& C_{\alpha}^{+}(Q, r)=\frac{A_{\alpha}^{+} D}{Q}+h_{\alpha}^{+}\left[\frac{Q}{2}+r-\mu\right]+\left(\frac{\pi_{\alpha}^{+} D}{Q} B(r)\right) \\
& C(Q, r)=\int_{0}^{1}\left(C_{\alpha}^{-}+C_{\alpha}^{+}\right) d \alpha .
\end{aligned}
$$

The minimum, the mean and the maximum values of the $Q$ represented by $Q_{1}, Q_{2}$ and $Q_{3}$, respectively, are calculated as follows,

$$
Q_{1}=\sqrt{\frac{2 D\left[A_{1}+\pi_{1} B(r)\right]}{h_{3}}} \quad Q_{2}=\sqrt{\frac{2 D\left[A_{2}+\pi_{2} B(r)\right]}{h_{2}}} \quad Q_{3}=\sqrt{\frac{2 D\left[A_{3}+\pi_{3} B(r)\right]}{h_{1}}}
$$


The possibilistic mean using (3) is then presented as follows,

$Q=\int_{0}^{1}\left(Q_{\alpha}^{-}+Q_{\alpha}^{+}\right) d \alpha$

Repeating the same concept applied in section 3.1.2 we have,

$u_{1}=1-\frac{h_{3} Q}{\pi_{1} D}, \quad u_{2}=1-\frac{h_{2} Q}{\pi_{2} D}, \quad u_{3}=1-\frac{h_{1} Q}{\pi_{3} D}, u=\int_{0}^{1}\left(u_{\alpha}^{-}+u_{\alpha}^{+}\right) d \alpha, r=F^{-1}(u)$.

The iterative process in section 3.2.1 is applied here to find optimal $Q$ and $r$. Fig.1. gives an overview of the inputs and outputs of the models.

Inputs Model outputs

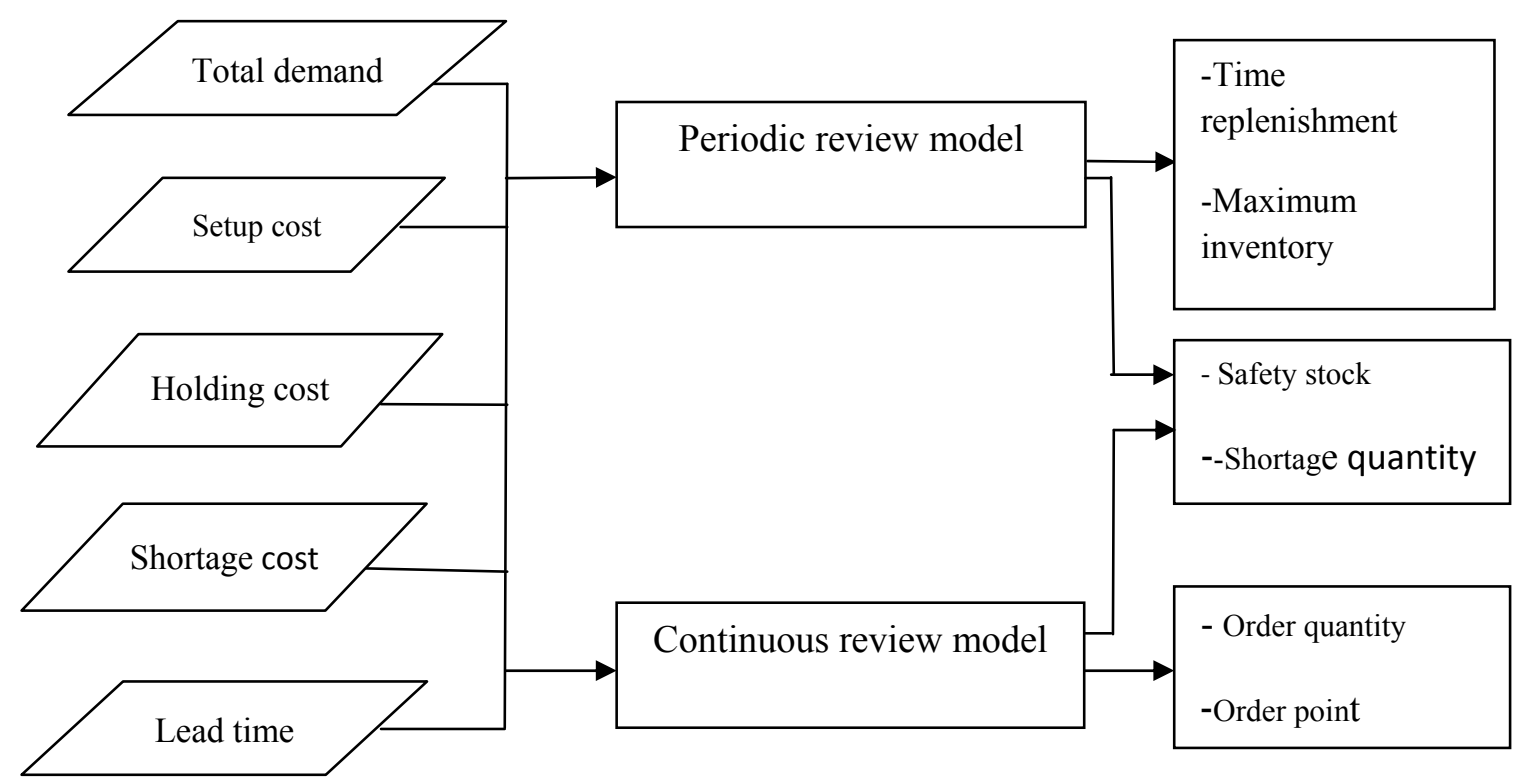

Fig.1. Inputs and outputs of the models

\section{Application in Iran Transfo}

In the previous sections, we have shown how to modify the crisp models for continuous and periodic review inventory systems in order to consider the fuzziness associated with the costs. Recently, there has been an increase interest on using fuzzy theory for real-world applications (Modarres et al. (2010). In order to validate and illustrate the results of the proposed models we have conducted an application in a private company called "Iran Transfo". We have also selected the most strategic items which constitute group products $A$ and $B$ in $A B C$ inventory classification. The total demand, the lead time and the fuzzy costs, as inputs, are shown in Table 2. Deficiency of any of these items leads to an interruption on manufacturing which causes approximately 35,000,000 US dollar. The results for both models, with both defuzzification methods are determined in Table 3 . 
Table 2

Input parameters

\begin{tabular}{ccccc}
\hline name & $\begin{array}{c}\text { Total } \\
\text { demand }\end{array}$ & $\begin{array}{c}\text { Lead time } \\
\text { (month) }\end{array}$ & Fuzzy setup cost & Fuzzy holding cost \\
\hline 1 & 4.488 & 4 & $(95000,100,000,103,000)$ & $(1000,1500,1800)$ \\
2 & 3240 & 1 & $(970010000,10200)$ & $(115,120,122)$ \\
3 & 960 & 5 & $(118,000,120,000,121,000)$ & $(580,600,620)$ \\
4 & 10800 & 6 & $(67,000,70,000,72,000)$ & $(285,300,310)$ \\
5 & 10320 & 6 & $(56,000,60,000,62,000)$ & $(200,225,250)$ \\
\hline
\end{tabular}

Table 3

The optimal solutions

\begin{tabular}{cccccccc}
\hline & & \multicolumn{3}{c}{ Periodic model results } & \multicolumn{3}{c}{ Continuous model results } \\
\hline \multirow{2}{*}{1} & Fuzzy method & $\mathrm{C}(\mathrm{R}, \mathrm{T})$ & $\mathrm{R}$ & $\mathrm{T}$ & $\mathrm{C}(\mathrm{Q}, \mathrm{r})$ & $\mathrm{Q}$ & $\mathrm{r}$ \\
& SDM & $2,556,900$ & 3078 & 54 & $2,288,800$ & 784 & 2229 \\
2 & $\alpha$-cut & $2,578,500$ & 3077 & 54 & $2,308,100$ & 790 & 2228 \\
& SDM & 159,720 & 1503 & 72 & 125,660 & 736 & 576 \\
3 & $\alpha-$ cut & 159,990 & 1504 & 72 & 125,870 & 735 & 577 \\
& SDM & $3,049,900$ & 9621 & 54 & $2,634,900$ & 1934 & 7622 \\
\multirow{2}{*}{4} & $\alpha$-cut & $2,975,400$ & 1023 & 54 & $2,621,700$ & 1832 & 7629 \\
& SDM & $1,544,900$ & 9867 & 72 & $1,399,100$ & 2300 & 7336 \\
5 & $\alpha-$-cut & $1,547,200$ & 9867 & 72 & $1,370,900$ & 2195 & 7341 \\
& SDM & 262,680 & 1266 & 216 & 230,280 & 644 & 577 \\
& $\alpha-$ cut & 272,630 & 1265 & 216 & 238,940 & 634 & 576 \\
\hline
\end{tabular}

\section{Decision support system}

In today's timeliness production environment, it is extremely important for the decision makers to have access to the decision support tools in order to make rapid and accurate decisions. In this section a decision support system is developed to efficiently use the models and corresponding iterative procedures and to analyze the effectiveness of the proposed approaches when tackling real world problem instances. The technological background of the system is illustrated in Fig. 2.

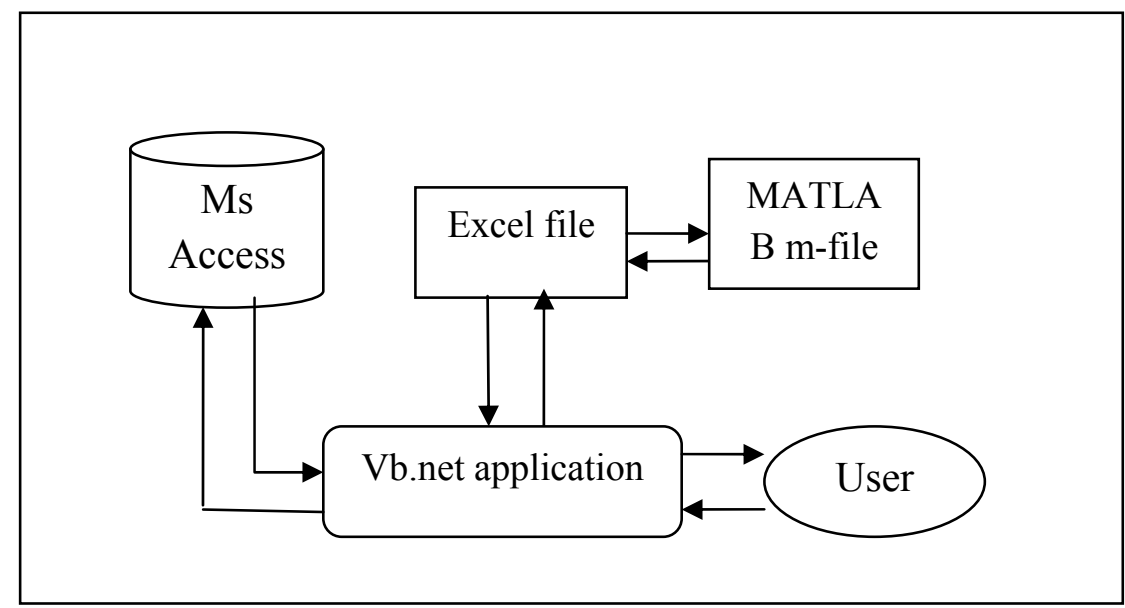

Fig. 2. The structure of DSS 
The proposed DSS model consists of three major components where the first one is a database component in which all inventory records are stored and can be modified for updates. The database is implemented with Microsoft access. The second component is a model based component which includes both continuous and periodic review models with user-defined parameters. The models and the procedures are written in MATLAB software. The third item is the user interface which is designed in Visual Basic. Transforming data between MATLAB and Visual Basic is performed by using an excel file as an intermediate to pass data between these two environments. The main interface window of DSS is given in Fig. 3. As we can observe, user can see the results for both models and choose the proper one according to their condition. Also user can choose the time period and see the optimal result foe from the selected period. The point is that both models perform the calculation using both defuzzification methods and the results for the method which yields the minimum cost are shown in the form.

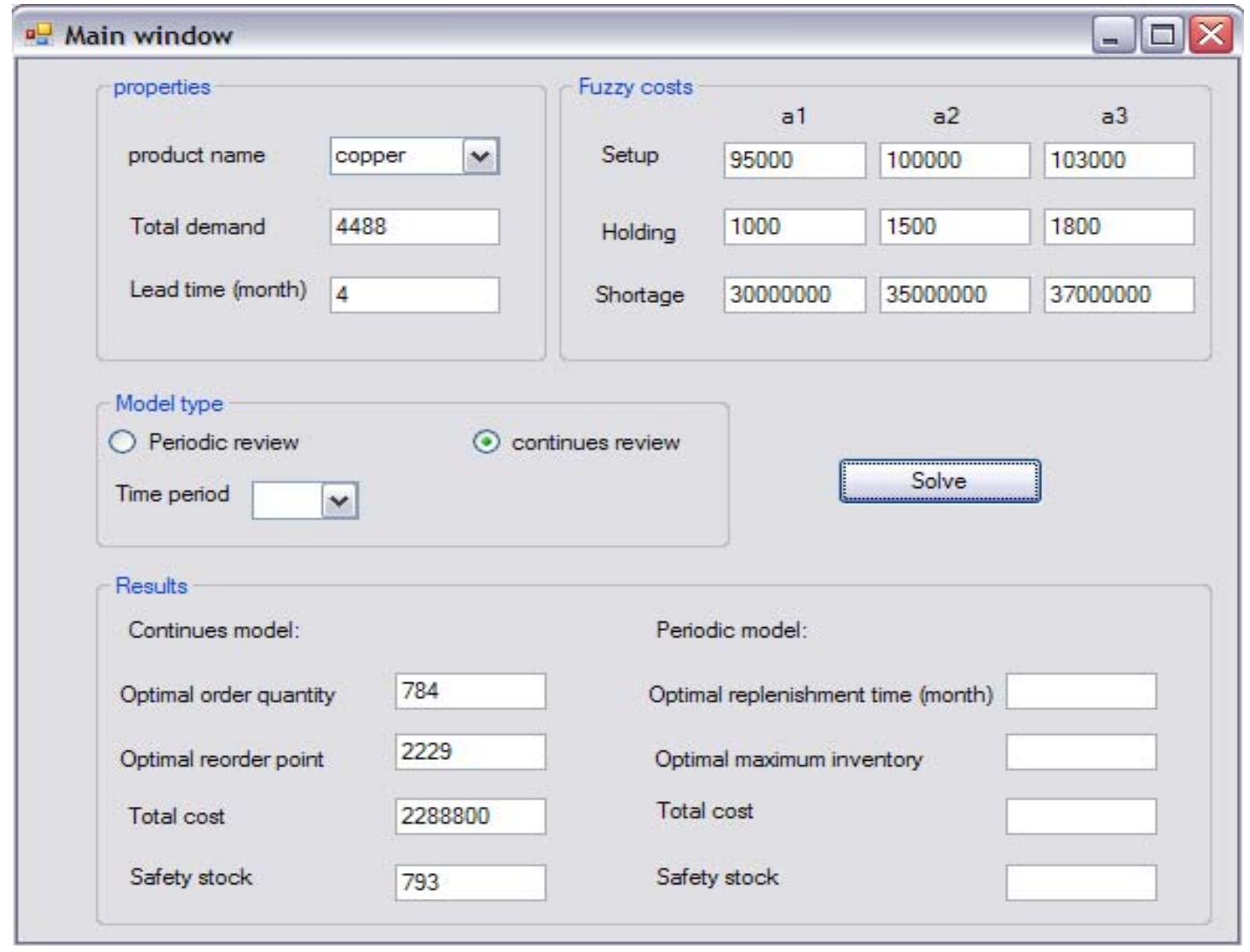

Fig. 3. The main form of the DSS

\section{Conclusion}

Incorporating fuzzy set theory and probability theory into inventory models potentiates the model to tackle real world fuzziness and randomness. In this article, we have applied the fuzzy set theory to reformulate the two periodic and continuous inventory models where shortages are backordered with shortage cost are incurred. Also, we have used the probabilistic theory to express the demand in the replenishment time. In both models, we have used the triangular fuzzy numbers to represent the imprecise setup cost, holding cost and shortage cost and obtained the model with fuzzy total cost. The 
periodic model gives the optimal values of review periods and maximum inventory levels and the continuous review model gives the optimal order quantity and order point. For these fuzzy models, we have employed two methods of defuzzification which are the signed distance and the possibilistic mean value. The implementation of the proposed method has also been illustrated using some numerical example. In addition, we have also proposed a decision support system with a user friendly interface, for efficient and effective use of the proposed models. Hence, the suggested inventory models are observed to be executable and useful for the decision maker in the real world.

\section{References}

Cakir, O. \& Canbolat, M. S. (2008). A web-based decision support system for multi-criteria inventory classification using fuzzy AHP methodology, Canada Expert Systems with Applications, 35, 1367-1378.

Chang, H-C., Yao, J-S. \& Ouyang, L-Y. (2004). Fuzzy mixture inventory model with variable leadtime based on probabilistic fuzzy set and triangular fuzzy number, Mathematical and Computer Modelling, 39, 287-304.

Day, O. \& Chakraborty, D. (2009). Fuzzy periodic review system with fuzzy random variable demand. European Journal of Operational Research, 198(1), 113-120.

Kao, C-K \& Hsu, W-K, (2002). Lot size-reorder point inventory model with fuzzy demands, Computers \& Mathematics with Applications, 43, 1291-1302.

Hadley, G., Whitin, T.M., (1963). Analysis of Inventory Systems. Prentice-Hall, New Jersey.

Handfield, R., Warsing, D. \& Wu, X. (2009). (Q,r) Inventory policies in a fuzzy uncertain supply chain environment, European Journal of Operational Research, 197(2), 609-619.

Lin, Y-J. (2008). A periodic review inventory model involving fuzzy expected demand short and fuzzy backorder rate, Computers \& Industrial Engineering, 54(3), Pages 666-676.

Modarres, M, Sadi-Nezhad, S \& Arabi, F. (2010), Fuzzy analytical hierarchy process using preference ratio: A case study for selecting management short course in a business school, International Journal of Industrial Engineering Computations, 1(2), 173-184.

Tütüncü, G. Y., Aköz, O., Apaydın, A. \& Petrovic, D. (2008). Continuous review inventory control in the presence of fuzzy costs, International Journal of Production Economics, 113(2),775-784.

Vijayan, T. \& Kumaran, M. (2008). Inventory models with a mixture of backorders and lost sales under fuzzy cost, European Journal of Operational Research, 189(1), 105-119.

$\mathrm{Wu}, \mathrm{K} . \&$ Yao, J-S., (2003). Fuzzy inventory with backorder for fuzzy order quantity and fuzzy shortage quantity, European Journal of Operational Research, 150(2), 320-352.

Yao, J-S. \& Lee, H-M. (1999). Fuzzy inventory with or without backorder for fuzzy order quantity with trapezoid fuzzy number, Fuzzy Sets and Systems, 105(3), 311-337.

Yao, J-S. \& Su, J-S. (2000). Fuzzy inventory with backorder for fuzzy total demand based on interval-valued fuzzy set, European Journal of Operational Research, 124(2), 390-408.

Yao, J-S. \& Chiang, J. (2003). Inventory without backorder with fuzzy total cost and fuzzy storing cost defuzzified by centroid and signed distance, European Journal of Operational Research, 148(2, 401-409.

Zadeh, L., (1965). Fuzzy sets, Information and Control, 8, 338-353. 